\title{
Determinants Of Vaccination Coverage In Malawi: Evidence From The Demographic And Health Surveys
}

\author{
Alister C. Munthali \\ Centre for Social Research, University of Malawi, Zomba. MALAWI \\ Email: amunthali@malawi.net
}

\section{Abstract}

The purpose of this paper is to identify groups of children in Malawi who are less or not reached by vaccination services by using data from the Demographic and Health Surveys conducted in Malawi in 1992, 1996, 2000 and 2004. These surveys have shown that the proportion of children aged 12 23 months who were fully vaccinated by 12 months of age has been decreasing: it was $67 \%$ in 1992 , then $55 \%, 54 \%$ and $51 \%$ in 1996, 2000 and 2004, respectively. The review has also shown that birth order of the child, residence (rural/ urban) and mother's education are major determinants of the immunization status of the child.

\section{Introduction}

Vaccination has been practised in Malawi since the arrival of the missionaries and colonial administrators. While these vaccinations were taking place, variolation against smallpox was also practised by the local people in some parts of the country for example in Ntchisi District in central Malawi. Prior to 1973, only smallpox vaccinations were given on a large scale while antigens such as BCG and DPT were provided in a few health facilities in the country. ${ }^{2}$ The Expanded Programme on Immunization (EPI) was officially launched in Malawi in 1979. The Malawi policy regarding EPI is to immunise all children under 12 months old with a goal of reducing morbidity and mortality due to six preventable diseases namely measles, tuberculosis, whooping cough, diphtheria, poliomyelitis and tetanus. ${ }^{3,4}$ In addition to these 6 diseases, the EPI has also included HepB and HIB.

While mission hospitals and other private health facilities are involved in the delivery of vaccination services, the Ministry of Health is by far the largest provider of vaccination services. Vaccination services in Malawi are delivered either through static or outreach clinics. The major purpose of establishing outreach clinics is to bring the vaccination services as close as possible to the clients of these services so that distance should not be the reason for the non-immunisation of children. With support from donors, and the civil society, Malawi has made tremendous progress in ensuring that the majority of the children under the age of 5 years are vaccinated.

\section{Aim}

The purpose of this paper is to examine the trends in vaccination coverage in Malawi between 1992 and 2004 and identify groups of children who are not or less reached by vaccination services in Malawi. It is important that people involved in the implementation of vaccination services should know the performance of the vaccination program so that they can better design interventions that can help to improve and sustain vaccination coverage. Appropriate interventions can also be designed in order to ensure that children who are not or are less reached by vaccination services are reached.

\section{Methodology}

The bulk of the data used in this paper was derived from the 1992, 1996, 2000 and 2004 Demographic and Health Surveys conducted by the National Statistical Office in collaboration with Macro International. These three surveys, which are nationally representative, provide national level data on vaccination coverage for each of the antigens including the proportion of children who are fully immunised. This paper examines the trends in vaccination coverage and further analyses the impact of sex of the child, birth order of the child, residence (whether rural or urban) and mothers' education on immunisation status of the child.

\section{Results}

Trends in vaccination coverage 1992-2004

National vaccination coverage in the early 1980s was relatively low. In 1981 coverage for BCG was estimated at 78\% while for DPT 3, Polio 3 and measles, it was $46 \%, 41 \%$ and $48 \%$, respectively. In 1984 , only $55 \%$ of the children under 12 months were fully immunised and this figure decreased to $35 \%$ in 1985.5

Table 1 Percentage of children 12-23 months who had received specific vaccines at time of survey

\begin{tabular}{|l|l|l|l|l|}
\hline Vaccine & $\begin{array}{l}1992 \text { DHS } \\
(\%)\end{array}$ & $\begin{array}{l}1996 \text { DHS } \\
(\%)\end{array}$ & $\begin{array}{l}2000 \text { DHS } \\
(\%)\end{array}$ & $\begin{array}{l}2004 \text { DHS } \\
(\%)\end{array}$ \\
\hline BCG & 97 & 98 & 92 & 91 \\
\hline Polio 3 & 88 & 91 & 80 & 78 \\
\hline DPT 3 & 87 & 89 & 84 & 82 \\
\hline Measles & 86 & 88 & 83 & 79 \\
\hline All & 82 & 81 & 70 & 64 \\
\hline
\end{tabular}

Table 1 above shows that there was no significant change in vaccination coverage for all vaccines for the period 1992 1996. Coverage remained largely stable during this period. However after 1996 it is apparent that vaccination coverage has been decreasing for all antigens. Vaccination coverage for BCG is higher than Polio 3 and DPT 3 and measles. BCG coverage is higher possibly because this is given at birth and in Malawi it is estimated that more than half of the pregnant women deliver in health facilities. Hence, children have the opportunity of receiving this vaccine soon after birth. It is also evident that the proportion of children aged 12-23 months who had received all vaccines at the time of the survey fell sharply from $82 \%$ in 1992 to $64 \%$ in 2000 .

Children are supposed to be fully vaccinated before they reach the age of 12 months. Table 2 below shows the percentage of children aged 12-23 months who received 
Table 2 Percentage of chikdren who have received specific vaccines by the age of 12 months

\begin{tabular}{|l|l|l|l|l|}
\hline Vaccine & $\begin{array}{l}1992 \\
\text { DHS (\%) }\end{array}$ & $\begin{array}{l}1996 \\
\text { DHS (\%) }\end{array}$ & $\begin{array}{l}\text { 2000 } \\
\text { DHS (\%) }\end{array}$ & $\begin{array}{l}2004 \\
\text { DHS (\%) }\end{array}$ \\
\hline BCG & 95 & 97 & 90 & 90 \\
\hline Polio 3 & 84 & 84 & 87 & 76 \\
\hline DPT 3 & 84 & 81 & 73 & 73 \\
\hline Measles & 70 & 68 & 79 & 63 \\
\hline All & 67 & 55 & 54 & 51 \\
\hline
\end{tabular}

specific vaccines by the age of 12 months:

It can be seen from Table 2 that, coverage for measles and polio 3 vaccines increased from $68 \%$ to $79 \%$ and $83 \%$ to $87 \%$, respectively for the period 1996 to 2000. Coverage for BCG and DPT 3 decreased from $97 \%$ to $90 \%$ and $81 \%$ to $73 \%$, respectively, for the same period. Overall the percentage of children aged 12-23 months who had received all the vaccines by the time they were 12 months old has been decreasing. In 1992, 67\% of the children aged 12-23 months were fully vaccinated by the time they reached 12 months of age and this decreased to 55\% in 1996, 54.0\% in 2000 and then $51 \%$ in 2004 . Using the results of the DHS, it is apparent that vaccination coverage has over the years been decreasing. It is therefore important to examine the factors that affect the immunization status of a child.

\section{Which children are reached or not reached by vaccination services?}

\section{Sex of child}

Table 3 below shows the percentage of children 12-23 by sex who were fully vaccinated at the time of the surver.

\begin{tabular}{|l|l|l|l|l|}
\hline Sex & $\begin{array}{l}1992 \text { DHS } \\
(\%)\end{array}$ & $\begin{array}{l}1996 \text { DHS } \\
(\%)\end{array}$ & $\begin{array}{l}2000 \text { DHS } \\
(\%)\end{array}$ & $\begin{array}{l}2004 \text { DHS } \\
(\%)\end{array}$ \\
\hline Male & 82 & 84 & 70 & 66 \\
\hline Female & 82 & 78 & 71 & 63 \\
\hline
\end{tabular}

Other studies have shown that girls are less privileged in terms of accessing social services including health and education. For example, with regard to vaccination services, it has been shown that in Bangladesh vaccination coverage rates for girls were less than that of boys by about $5 \%$ throughout the 1990s. ${ }^{6}$ However, in Malawi, as can be seen from Table 3 above, the percentage of female children aged 12-23 months who were fully vaccinated at the time of the survey in 1992 and 2000 was equal to the percentage of male children in the same age group who were fully vaccinated. In 1996 and 2004, however, there were more male children who were fully vaccinated at $84 \%$ and $66 \%$ compared to female children at $78 \%$ and $63 \%$, respectively. It is therefore not conclusive that male children have higher vaccination coverage than females.

\section{Birth order}

Birth order seems to be an important determinant of vaccination status of under-five children. In other parts of the world it has been shown that there exist a strong association between immunization status and birth order; with children born into larger families having a low vaccination uptake ${ }^{7}$; and first born children being more likely to be immunized on time than second born children. ${ }^{8}$ Table 4 below shows the vaccination coverage rate for children of a particular birth order in Malawi.

Table 4 Percentage of childrenaged 12-23 who are fully vaccinated by birth order

\begin{tabular}{|l|l|l|l|l|}
\hline Age & $\begin{array}{l}1992 \text { DHS } \\
(\%)\end{array}$ & $\begin{array}{l}1996 \text { DHS } \\
(\%)\end{array}$ & $\begin{array}{l}2000 \text { DHS } \\
(\%)\end{array}$ & $\begin{array}{l}2004 \text { DHS } \\
(\%)\end{array}$ \\
\hline 1 & 90 & 89 & 79 & 72 \\
\hline 2 to 3 & 85 & 83 & 72 & 64 \\
\hline 4 to 5 & 81 & 79 & 70 & 63 \\
\hline $6+$ & 75 & 74 & 58 & 58 \\
\hline
\end{tabular}

It can be seen from Table 4 above that while vaccination coverage seems to be decreasing, vaccination coverage among those who are first born children is higher than those who are born later. For example, in $200079 \%$ of the first born children aged 12-23 months were fully vaccinated compared to $58 \%$ of the children who were 6 th or above in the birth order. In 1996, 89\% of the first born children were fully vaccinated compared to $74 \%$ of those children who were 6 th + in the birth order. Hence, as other studies have shown, in Malawi birth order seems to be an important determinant of vaccination status with first born children more likely to be vaccinated than those who are not.

\section{Residence}

Table 5 below shows vaccination status of children aged 12-23 months by place of residence:

\begin{tabular}{|l|l|l|l|l|}
\hline Residence & $\begin{array}{l}1992 \text { DHS } \\
(\%)\end{array}$ & $\begin{array}{l}1996 \text { DHS } \\
(\%)\end{array}$ & $\begin{array}{l}2000 \text { DHS } \\
(\%)\end{array}$ & $\begin{array}{l}2004 \text { DHS } \\
(\%)\end{array}$ \\
\hline Rural & 81 & 80 & 69 & 64 \\
\hline Urban & 87 & 88 & 79 & 71 \\
\hline
\end{tabular}

In 1992, 1996, 2000 and 2004, the percentage of children who were fully vaccinated in urban areas was higher than in rural areas. For example, in 2000, only $69 \%$ of the children in rural Malawi were vaccinated fully at the time of the survey while in urban areas the percentage was much higher at $79 \%$. The corresponding percentages were $80 \%$ and $88 \%$ in 1996 and $81 \%$ and $87 \%$ in 1992 . In $2004,64 \%$ of the children in rural areas were fully vaccinated at the time of the survey compared to $71 \%$ in the urban areas. This generally shows that children in urban Malawi are more likely to complete the immunization schedule successfully than those children in rural areas. This is most likely related to the problems of accessing health facilities in rural areas compared to urban areas in Malawi. For example the DHS reports that $51 \%$ of the women are within 5 kilometres of a health facility and $18 \%$ are 10 kilometres or more away from a health facility. The median distance to the nearest health facility is $5 \mathrm{~km}$. As expected, urban dwellers are nearer to facilities (median $=2.7$ $\mathrm{km}$ ) than rural residents (median $=6.2 \mathrm{~km}$ ).

There were also some regional differences in terms of vaccination coverage as can be seen from Table 6 below:

It is apparent that more children in the southern region and northern region are likely to be vaccinated than in the 
Table 6 Percentage of children 12-23 months who were fully vaccinated by region

\begin{tabular}{|l|l|l|l|l|}
\hline Region & $\begin{array}{l}1992 \mathrm{DHS} \\
(\%)\end{array}$ & $\begin{array}{l}1996 \mathrm{DHS} \\
(\%)\end{array}$ & $\begin{array}{l}2000 \mathrm{DHS} \\
(\%)\end{array}$ & $\begin{array}{l}2004 \mathrm{DHS} \\
(\%)\end{array}$ \\
\hline North & 80 & 82 & 78 & 73 \\
\hline Central & 80 & 73 & 61 & 57 \\
\hline South & 84 & 90 & 77 & 69 \\
\hline
\end{tabular}

central region. On average the central region has the lowest vaccination coverage. For example in 2000, while $78 \%$ and $77 \%$ of the children aged $12-23$ in the northern and southern regions, respectively, were fully vaccinated, in the central region only $61 \%$ were fully vaccinated. In $2004,73 \%$ of the children in the northern region and $69 \%$ of those in the southern region were fully vaccinated at the time of the survey compared to only $57 \%$ in the central region.

\section{Mother's education}

An earlier study found that taking children for immunisation is the responsibility of mothers and not fathers. It also pointed out that there are some exceptions for example when mothers are ill or when the couple has twins when men can take their children for vaccination. Breastfeeding children may require to be breastfed when taken for immunisation, a duty that men cannot fulfil. ${ }^{9}$ It is therefore important that mothers should understand the importance of vaccinations as they are the ones who are endowed with the responsibility of taking children for vaccinations. In order to demonstrate the impact of educational attainment on vaccination coverage, Table 7 below shows the percentage of children aged 12 23 months who had received all the vaccines by educational level of the mother.

Table 7 Perecentage of children aged 12-23 months who had received vaccines by education status of mother

\begin{tabular}{|l|l|l|l|l|}
\hline $\begin{array}{l}\text { Educational } \\
\text { status of } \\
\text { mother }\end{array}$ & $\begin{array}{l}1992 \text { DHS } \\
(\%)\end{array}$ & $\begin{array}{l}1996 \text { DHS } \\
(\%)\end{array}$ & $\begin{array}{l}2000 \text { DHS } \\
(\%)\end{array}$ & $\begin{array}{l}2004 \text { DHS } \\
(\%)\end{array}$ \\
\hline No education & 76.3 & 76.5 & 64 & 55 \\
\hline $\begin{array}{l}\text { Primary } \\
\text { Level 1-4 }\end{array}$ & 84.5 & & 66.5 & 61 \\
\hline $\begin{array}{l}\text { Primary } \\
\text { Level 5-8 }\end{array}$ & 89.2 & 85.1 & 75.1 & 69 \\
\hline Secondary + & 96.3 & 83.6 & 87.5 & 84 \\
\hline
\end{tabular}

Table 7 shows that the higher the level of education attained by mothers, the higher the likelihood that their children will be vaccinated. For example in $2000,88 \%$ of the mothers who had attained a secondary school education and higher had their children fully vaccinated compared to $64 \%$ of the mothers who had no education. The same trend was observed in 1992 and 1996 Demographic and Health Surveys. In 2004 $84 \%$ of the children whose mothers had secondary school+ level of education were fully vaccinated at the time of the survey compared to $55 \%$ of the children whose mothers had no education. This therefore shows that education of the mother is an important determinant of immunization status of the child.

\section{Discussion and Conclusion}

This paper concentrated on univariate analysis. However there are opportunities of performing multivariate analysis. Despite this shortfall, this paper has however highlighted the inequalities in terms of access to vaccination services. Unlike in other countries where girls are disadvantaged, the Demographic and Health Surveys upon which this paper is based have shown that there are no significant differences between girls and boys in terms of vaccination coverage. However, birth order is an important determinant of immunization status of a child with first born children being more likely to be fully vaccinated and on time than those who are not first born children. The importance of vaccination needs to be emphasized to all mothers and caretakers of children so that children who are born later are also vaccinated and at the right time.

This paper has also shown that less children in rural areas are vaccinated compared to those in urban areas. As has been discussed, one of the major reasons for this is the limited number of facilities in rural areas. The Government of Malawi has introduced outreach clinics in order to bring vaccination services closer to the people. The delivering of vaccination services is hampered by lack of transport for the vaccinators and inaccessibility of certain outreach clinics by vaccinators and clients especially during the rainy season. ${ }^{10,11}$ Improving road networks, provision of reliable transport for vaccinators and increasing the number of outreach clinics would increase the uptake of vaccination services especially in rural Malawi.

Mothers' education is another important determinant of the immunization status of the child. Vaccination coverage is higher for those children whose mothers are more educated. This is possibly because educated mothers are in a better position to understand the importance of vaccination. Since mothers with secondary school education and above are the ones more likely to have their children vaccinated, it is important that government should make secondary school compulsory. Finally, it is also important that the Ministry of Health should ensure that vaccines are always available in the health facilities and that providers should be friendly to their clients as these affect the uptake of services.

\section{Acknowledgement}

I would like to thank Measure DHS and National Statistical Office for allowing me to use the data from the Demographic and Health Surveys conducted in 1992, 1996 and 2000. This data set can be requested from NSO and MACRO Inc.

\section{References}

1. Chilowa, W. and A. Munthali. (1998). A study of vaccination cultures, social demand for immunization and practices of vaccination regimes: Ntchisi District report. Zomba: Centre for Social Research.

2. Chilowa, W. and A. Munthali. (1999). Immunisation in Malawi: quality of care, social demand and sustainability of vaccination services. Amsterdam: Het Spinhuis.

3. Chilowa, W. and A. Munthali. 1999. Immunisation in Malawi: quality of care, social demand and sustainability of vaccination services. Amsterdam: Het Spinhuis. 
4. Vaahtera, M., T. Kulmala, K. Maleta, T. Cullinan, M.L. Salin and P. Ashorn. (2000). Childhood immunisations in rural Malawi: the time of administration and predictors of non-compliance. Annals of Tropical Paediatrics 20:305-312.

5. Ministry of Health. (1991). Expanded programme on immunization. Lilongwe: EPI Unit, Ministry of Health.

6. Chowdhury, A.M.R. (2002). Who gets vaccinated in Bangladesh? The immunization divide. Dahka: Bangladesh Health Equity Watch.

7. Barreto, T.V. and L.C. Rodriques. (1992). Factors influencing childhood immunisation in an urban area of Brazil. J. Epidemiology Community Health 46(4):357-61.
8. Schaffer, S.J. and P.G. Szilagyi. (1995). Immunisation status and birth order. Arch Pediatr Adolescent Med. 149(7): 792-7.

9. Chilowa, W. and A. Munthali. (1998). A study of vaccination cultures, social demand for immunization and practices of vaccination regimes: Ntchisi District report. Zomba: Centre for Social Research.

10. Ministry of Health. (2003). EPI comprehensive review. Lilongwe: EPI Unit.

11. Chilowa, W. and A. Munthali. 1999. Immunisation in Malawi: quality of care, social demand and sustainability of vaccination services. Amsterdam: Het Spinhuis.

\section{Guidance for National Tuberculosis Programmes on the management of tuberculosis in children \\ - an update}

\section{Steve M Graham}

Department of Paediatrics, College of Medicine, Blantyre

Email: mulanje_45@yahoo.com

\section{Abstract}

About one million children develop tuberculosis (TB) annually worldwide. Childhood TB is common in Malawi accounting for about $12 \%$ of all TB cases. Childhood TB differs from TB in adults in ways that have important implications for the prevention, diagnosis and treatment of $\mathrm{TB}$ in children. Young children living in close contact with a case of smearpositive pulmonary TB are at particular risk of infection and TB disease. Screening of the household contacts of an infectious source case is therefore recommended to identify children with TB and enable their prompt treatment, and to provide children who do not have TB with isoniazid preventive treatment. It is recognised that there is a need to improve the diagnosis and management of children with $\mathrm{TB}$, the prevention of $\mathrm{TB}$ in children and to ensure their inclusion under the implementation of the Stop TB strategy by National TB Programmes. A subgroup of the WHO DOTS Expansion Working Group called the Stop TB Partnership Childhood TB Subgroup published guidelines for the management of child TB in 2006. The guidelines are designed to complement current national and international guidelines on the implementation of the Stop TB Strategy and existing guidelines, but also to fill existing gaps to ensure that children with M. tuberculosis infection and TB disease are identified early and managed effectively. This paper summarises some of the most important information and recommendations put forward in those guidelines.

\section{Introduction}

A nationwide survey by the Malawi National Tuberculosis Control Programme (NTP) was undertaken in 1998 and reported that $12 \%$ of all TB cases were children. ${ }^{1}$ Difficulties with diagnosis make it difficult to be certain as to how accurately this reflects the true burden of TB disease in Malawian children. However, it is consistent with global estimates and what might be expected in a TB endemic country such as Malawi where sputum smear positive disease is common. ${ }^{2}$ The source of infection of most children is an infectious adult in their close environment (usually the household). In the majority of cases, the resultant cellmediated immunity contains the disease process at this stage. Risk of disease progression is increased in the very young and in immune compromised children such as those with HIV or severe malnutrition. Progression of disease occurs by 1) extension of the primary focus with or without cavitation; 2) the effects of pathological processes caused by the enlarging lymph nodes or by 3 ) lymphatic and/ or haematogenous spread.

Implementation of the Stop TB Strategy ${ }^{3}$ (see Table 1), which builds on the DOTS strategy developed by the World Health Organization (WHO) and the International Union Against Tuberculosis and Lung Disease has a critical role to play in reducing the worldwide burden of disease and thus in protecting children from infection and disease. The management of children with TB should be in line with the Stop TB Strategy, taking into consideration the particular epidemiology and clinical presentation of TB in children.

For NTPs to successfully manage TB in children, standardised approaches based on the best available evidence are required. The engagement of all who provide care to children (including paediatricians and other clinicians) is crucial. These standardised approaches need to be incorporated into existing guidelines and strategies that have been developed by NTPs. Reducing the burden of TB in children will require changing and improving many existing practices, such as those that relate to contact investigations.

\section{Diagnosis}

The diagnosis of TB in children relies on careful and thorough assessment of all the evidence derived from careful history, clinical examination and relevant investigations, e.g., the tuberculin skin test (TST), chest radiograph (CXR) and sputum smear microscopy. Although bacteriological confirmation of TB is not always possible, it should be sought whenever possible, e.g., by sputum microscopy in children with suspected pulmonary TB who are old enough to produce a sputum sample. A trial of treatment with TB medications is not recommended as a method of diagnosing TB in children. The decision to treat a child should be carefully considered, and once such a decision is made, the child should be treated with a full course of therapy.

Most children with TB have pulmonary TB. The proposed approach to the diagnosis of TB in children (Table 2) is based on limited published evidence and rests heavily on expert opinion. In most immunocompetent children, TB presents with symptoms of a chronic disease after they have been in contact with an infectious source case. Infection with 